\title{
Otras noticias
}

\section{Distinciones a nuestros músicos}

En 2008 el director de orquesta Francisco Rettig obtuvo un Grammy Latino como Mejor Álbum instrumental, CD grabado por él, conduciendo a la Orquesta Filarmónica de Bogotá.

En marzo de 2009 la Confederación Internacional de Sociedades de Autores y Compositores (CISAC), con sede en París y que agrupa 222 sociedades en el mundo, eligió a Santiago Schuster como nuevo Director Regional de la entidad para América Latina y el Caribe, cargo que asumió el 1 de abril en Buenos Aires.

El 21 de abril de 2009, en el Centro Cultural Teatro la Cúpula, se realizó la décima entrega del premio Altazor 2008, gala convocada por la Sociedad Nacional de Autores de Teatro, Cine y Audiovisuales (ATN), la Sociedad Chilena de Intérpretes (SCI) y el Colegio de Profesionales de la Danza (Prodanza Chile). Los premiados fueron: Sebastián Errázuriz, en la categoría "música alternativa"; Alexis Venegas, en la categoría "pop balada”; Mauricio Redolés, en "rock”; Manuel Sánchez, en "música folclórica", y Manuel Jiménez, en "ejecución musical".

El 27 de abril de este año, en el auditorio del Instituto de Chile, se efectuó la entrega del "Premio Domingo Santa Cruz" a la cantante Miryam Singer y al señor Eduardo Tironi, y el "Premio Academia" al ex Director de la Sociedad Chilena del Derecho de Autor, Santiago Schuster, ambos galardones otorgados por la Academia de Bellas Artes. El acto estuvo presidido por el Presidente de dicha Academia, el compositor Santiago Vera Rivera.

El 25 de mayo, en el auditorio del Instituto de Chile, se realizó la sesión pública y solemne en la cual el guitarrista Luis Orlandini fue recibido como Miembro de Número de la Academia Chilena de Bellas Artes del Instituto de Chile. En esa oportunidad Luis Orlandini desarrolló el tema "La interpretación musical". El discurso de recepción al nuevo Académico estuvo a cargo del presidente de la Corporación, compositor Santiago Vera Rivera.

A fines de mayo se recibió la noticia que el compositor Jorge Arriagada estaba nominado como Mejor Compositor de Música de Cine por la Sociedad de Autores de Francia, país donde se encuentra radicado el músico chileno.

El 27 de agosto de 2009 se realizó la ceremonia en la que el Rector de la Universidad de Chile entregó la Distinción Académica de Profesor Emérito de dicha Universidad, al académico de la Facultad de Artes, Profesor Cirilo Vila Castro. En este acto, que se enmarcó dentro de las actividades del $80^{\circ}$ aniversario de la Facultad de Artes, también recibió la misma distinción el Profesor Fernando González Mardones, quien agradeció a nombre de ambos premiados.

Con ocasión de las Fiestas Patrias, la presidenta de la República Michelle Bachelet distinguió a Eleodoro y Marcial Campos (Los Hermanos Campos) con la Orden al Mérito Docente y Cultural Gabriela Mistral, en el grado de Gran Oficial, por su destacada trayectoria y aporte a la música chilena. El dúo folclórico celebra más de 70 años en la carrera musical.

\section{Compositores chilenos en el ballet, teatro y cine}

En el mes de abril de 2009 el Ballet Nacional Chileno, que dirige Gigi Caciuleanu, realizó una gira a Bolivia y Uruguay. En Bolivia se presentó en el Festival Internacional de Teatro de Santa Cruz de la Sierra, ofreciendo las coreografías de Caciuleanu, Valparaíso Vals, con música de Ángel Parra, Osvaldo Rodríguez, Eduardo Yáñez, Luis Advis, Violeta Parra, Desiderio Arenas y otros, y París-Santiago, con música del grupo Los Jaivas. En Uruguay, en el Teatro Solís de Montevideo, la compañía presentó dos funciones de Valparaíso Vals, y luego itineró por otras seis ciudades uruguayas.

Del 2 al 6 de junio, en el Teatro Municipal de Santiago, se presentó el Ballet de Santiago, con 30\& TR 35 horas Bar del coreógrafo Eduardo Yedro, sobre música de Los Tres.

El 3 de junio, en el Patio de las Camelias del Palacio de la Moneda, se realizó la ceremonia de entrega de la nacionalidad por gracia a la maestra Joan Turner, viuda de Víctor Jara, por la Presidenta de la República. En esa ocasión la Compañía de Danza Espiral presentó la coreografía de Patricio Bunster A pesar detodo, con música de Víctor Jara. 
El 12 de junio, en el Teatro de Wuppertal, Alemania, el Tanztheater interpretó, poco días antes de su muerte, la nueva coreografía que Pina Bausch dedicó a Chile. La pieza, de más de dos horas de duración, que incluye música de Víctor Jara, Violeta Parra, Congreso y Cecilia, al morir la coreografía, aún no tenía un título definitivo.

En el Teatro Regional del Maule, Talca, el 3 de abril, se interpretó Una relación pornográfica, de Philippe Blasband, dirigida por Paulo Meza, con música incidental de Luis Cast y coreografías de Francisca Sazié. En el mismo escenario, el 29 de abril, dirigida por Raúl Osorio, se presentó Porque sólo tengo este cu erpo para defen der este coto, de Juan Claudio Burgos, con música de Miguel Ángel Bravo.

El 17 de junio el Teatro Nacional Chileno estrenó, en el Teatro Antonio Varas, Tres M arías y una Rosa, de David Benavente y el Taller de Investigación Teatral (TIT). La obra fue dirigida por Raúl Osorio, y Patricio Solovera compuso la música.

El 8 de julio se realizó la avant-première, en la Sala Jorge Müller del Instituto de la Comunicación e Imagen de la Universidad de Chile, de la película El húsar dela muerte, con música de Sergio Ortega. Esta cinta pudo ser restaurada gracias al apoyo del Fondo de Fomento de la Música Nacional.

Los días 12 y 13 de septiembre, en la Estación Mapocho, actuó el Ballet Nacional Chileno presentando la coreografía de Gigi Caciuleanu Valparaíso vals, con la participación de la cantante Isabel Aldunate. La música empleada en este ballet es de Ángel Parra, Dióscoro Rojas, Osvaldo Rodríguez, Eduardo Yáñez, Violeta Parra, Luis Advis y otros.

\section{L ibros recientemente publicados}

El 14 de abril de 2009, en el Auditorio de la Facultad de Ciencias Sociales de la Universidad de Chile, se presentó el libro M úsica en tensión: producción simbólica en tiempos deglobalización, de Simón Palominos Mandiola, Elías Farías Caballero y Gonzalo Utreras Vargas, investigadores del Centro de Estudios CRANEO. Este libro fue financiado por el Fondo de Fomento de la Música Nacional.

La RM Ch ha recibido el libro M odernidad, posmodernidad e identidad del jazz en Chile: El caso de la generación de 1990 y Ángel Parra, de Álvaro Menanteau, editado por la Facultad de Artes, Departamento de Musicología, Universidad de Helsinki, Studia Musicologica Universitatis Helsingiensis XVIII, Helsinki, 2009.

El 29 de septiembre, en la Sala de Cine del Centro Cultural Palacio de La Moneda, se presentó la edición chilena de El libro mayor de Violeta Parra, de Isabel Parra. Presentaron el libro los académicos María Nieves Alonso y Gastón Soublette. En la ocasión, la cantautora Isabel Parra, acompañada de Tita y Antar, interpretaron temas de su última antología musical A fectos y compromisos.

Con el aporte del Fondo de Desarrollo de las Artes y la Cultura se ha editado en Valparaíso -y se encuentra en circulación- el Álbum para el músico contemporáneo, de los compositores Ricardo Silva y Christian Donoso. El Álbum consiste en diez piezas breves para piano, cinco de cada autor. La partitura está acompañada por un CD de las diez piezas.

\section{N uevos fonogramas en circulación}

En junio de 2009 el sello discográfico Pueblo Nuevo cumple cuatro años de existencia. Las grabaciones que edita se encuentran en: www.pueblonuevo.cl y su catálogo comprende varios compositores chilenos de música docta, tales como Gustavo Becerra, José Miguel Candela y otros. A comienzos de abril de este año Pueblo Nuevo editó un fonograma titulado Life on M ars, del compositor danés, miembro honorario de la Asociación Nacional de Compositores de Chile, Lars Graugaard.

El 10 de mayo, en el Galpón Víctor Jara, se lanzó el CD Ciclo electroacústico Salvador Allen de Gossens de José Miguel Candela. La obra cuenta con 8 piezas mixtas y un microciclo acusmático, titulado Un camino nuevo. Las piezas del Ciclo son: 1. Sigan ustedes sabiendo (Mauricio Valdebenito, guitarra acústica), 2. que mucho más temprano (Alejandro Ramírez, batería), 3. que tarde (Randall Ledermann: dizi chino), 4. denuevo se abrirán (José M. Candela: bajo electrónico fretless), 5 . las grandes alamedas (Héctor Cerda: guitarra eléctrica), 6. por don depase (Exequiel Gómez: intérprete corporal, en espacio de sensores) 7. el hombre libre (Gonzalo Cuadra: voz), y 8. para construir una sociedad mejor (obra interactiva. Ricardo Vega: programación de interfaz). Las 4 piezas que forman el microciclo son: 9 . N osotros estamos seren os y tranquilos, 10. H aremos posiblela gran tarea, 11. H emos heredado la forma irracional y 12. Seremos lo suficientemente fuertes. En el acto de lanzamiento del CD se escucharon algunas de sus partes. 
El 15 de mayo, en la Sala Isidora Zegers, se efectuó la presentación del disco compacto Elisa Alsina, piano, proyecto de creación e investigación artística de la Vicerrectoría de Investigación de la Universidad de Chile. La destacada pianista chilena incluyó en su CD obras de Mozart, Chopin, Schumann y las Cinco doloras del compositor chileno Alfonso Leng. Los comentarios sobre el disco, que se presentó en esa ocasión estuvieron a cargo del musicólogo Dr. Luis Merino.

El 31 de agosto, en el Salón Cardenal Juan Francisco Fresno del Centro de Extensión de la Pontificia Universidad Católica de Chile, se presentó el CD Desdela raíz, grabado por los Huasos de Algarrobal. El disco contiene 16 piezas representativas del alma popular de nuestro país.

\section{Premio de Composición Casa de las A méricas 2009}

El jurado del Premio de Composición de Casa de las Américas 2009, formado por Rafael Aponte Ledée (Puerto Rico), Dina Arismendi (Venezuela), Tulio Peramo (Cuba), Roberto Valera (Cuba) y Alberto Villalpando (Bolivia) se reunió en el mes de abril, en La Habana, para analizar los 22 cuartetos de cuerdas procedentes de nueve países de América Latina. El 17 de abril acordó otorgar por unanimidad el Premio de Composición 2009 a la obra Bestiario, de Fabián Harbeith Roa Dueñez, de Colombia, y Mención a la obra Desfragmentación, del mexicano Alejandro Javier Padilla Gallegos. El jurado señaló que "todas las obras presentadas demuestran un alto nivel profesional y valor artístico, por lo que recomienda difundir dicho repertorio entre los cuartetos de cuerdas de América Latina y el mundo".

\section{H omenajea L uis Advis}

El 21 de septiembre, en las Sala SCD Bellavista, se realizó un homenaje al compositor y ex presidente de la SCD, Luis Advis, al cumplirse el quinto año de su deceso. Dicha ceremonia, a la que asistió la familia del compositor y numeroso público, estuvo presidida por el compositor Alejandro Guarello, presidente de la SCD.

En la ocasión, el subdirector de la R M Ch, Fernando García, expresó lo siguiente: "El tango declara que 20 años no son nada, menos son 5, sin embargo la ausencia del colega Advis -o mejor del 'coleguita', como él llamaba cariñosamente a los músicos- ha sido bastante larga si pensamos cuanto más habría realizado en 5 años con el talento, la imaginación, la capacidad de trabajo que poseía.

Pero hay que decir que el 'coleguita' Lucho no era sólo-afortunadamente- un trabajador empedernido, también era un buen conversador. En su juventud santiaguina le tocó vivir los tiempos de los Cafés, donde se arreglaba o desarreglaba el mundo. Hombre inteligente, de vasta cultura, informado, cordial, 'buena persona' -como decimos por estos lados- permitía y estimulaba el diálogo diverso. Hasta los 'coleguitas' -tan monotemáticos- no hablábamos únicamente de música, y, al finalizar la charla, salíamos más ilustrados y amigos con Luis que antes de comenzarla. Esa inmensa calidad humana hacía que por momentos olvidáramos los méritos musicales del 'coleguita' Lucho, pero su talento era tanto, que ese olvido poco duraba.

Los condiscípulos de Luis Advis en las clases de Gustavo Becerra recordamos que fue él, el 'coleguita' Lucho, estudiante de filosofía, quien empujó al maestro -según propia confesión- a sumergirse en el intrincado universo de la lógica formal, desarrollando un novedoso método de análisis de la música. Es decir, nuestro buen amigo, a quien recordamos hoy, fue partícipe de un importante avance en los estudios teórico-musicales. Mas, era en la composición donde Luis Advis mostraba su gran talento.

Cualquiera fuese el género que abordara, algo tenía su música que despertaba interés en el auditor. A la distancia pienso que ese 'algo' era un profundo entronque con su tierra y con el momento histórico que vivía.

En el transcurso del siglo 20 en Chile hemos experimentado tres instantes en que la música de tradición oral y la de tradición escrita se han encontrado. Son períodos de búsqueda de nuestra identidad, de acentuación del mestizaje. Tres momentos en que los compositores doctos han 'descubierto' la música popular, han palpado sus raíces. El primero fue en las décadas de comienzos de siglo, cuando varios en Hispanoamérica celebrábamos el Centenario; cuando se producía la revolución agraria en México y se dictaba la Constitución de 1917, fenómeno que fue observado con atención por los pueblos americanos; cuando comenzó a tomar fuerza el movimiento obrero en nuestro país y se fundaron la Federación Obrera de Chile y el Partido Obrero Socialista; cuando llegaron nuevos aires, en 
1920, a la vida política nacional. Ese fue el minuto en que compositores como Pedro Humberto Allende, Carlos Lavín, Carlos Isamitt estudiaron y sumaron a su discurso la música mapuche. Los chilenos comenzamos entonces a reconocer como propia la música de uno de los antiguos habitantes de Chile.

Un nuevo instante de acercamiento de las músicas en busca de una identidad propia se produjo a mediados del siglo pasado. Era época de gran efervescencia social en América Latina. En 1959 triunfó la Revolución Cubana y en otros países se instalaron gobiernos militares progresistas. En Chile avanzaban los sectores que exigían cambios en la sociedad y que alcanzaron la presidencia con Salvador Allende. Esos fueron los tiempos en que Roberto Falabella incorporó los cantos populares del Norte Grande a la música docta y Ramón Campbell las expresiones musicales de Isla de Pascua. Se agregaron, así, nuevas informaciones sonoras al repertorio que identificamos como nuestro. Fue la época en que Luis Advis llegó desde Iquique a Santiago e hizo valiosos aportes al reconocimiento de nuestra música nortina, pues también eligió el camino de sintetizar, de mezclar lo docto con lo popular.

El tercer instante de acercamiento de lo popular y lo docto aún lo vivimos. Comenzó en la década de 1980, en los momentos en que la dictadura se debilitaba y se profundiza la globalización capitalista de la economía, que trajo consigo los tratados de Libre Comercio (TLC). En los años 90 una delegación encabezada por Luis Advis, entonces presidente de la SCD, se reunió con el Ministro de Educación para explicarle los peligros que entrañaba el TLC, tal cual se discutía en el Parlamento. Al tener Chile una industria y una vida musical débiles, habría cesantía entre los músicos y peligraba la existencia misma de la música chilena. Felizmente, fuimos escuchados y se hicieron algunos cambios en el TLC. Durante estos años jóvenes y talentosos creadores de música de tradición escrita han ido buscando en la música de los pueblos australes o de otros grupos étnicos (kaweskar, yaganes, selk'man, atacameños) nuevos elementos identitarios. Recién en el siglo 21 los chilenos hemos terminado por reconocer, como parte de nosotros, a las etnias que habitaban Chile al arribo de los europeos.

Es esa síntesis entre música de tradición escrita y de tradición oral lo que buscó Luis Advis. Es esa hibridación de lo popular con lo docto lo que indagó el compositor. Es esa manera mestiza latinoamericana, masiva, la que le complació y sirvió para expresarse. Él lo declaró: 'Esta mezcla rara que hago es la que me gusta: esta mezcla de lo docto y lo popular. No sé por qué, pero me gusta, me entretiene'. Está claro: Luis Advis fue un hombre de su pueblo y de su tiempo. Su música lo confirma. Escuchémosla”. 